\title{
CONVERSATIONS ON THE DARK SECRETS OF PHYSICS
}




\title{
CONVERSATIONS ON THE \\ DARK SECRETS OF PHYSICS
}

\author{
Edward Teller \\ Wendy Teller \\ and \\ Wilson Talley
}

SPRINGER SCIENCE+BUSINESS MEDIA, LLC 


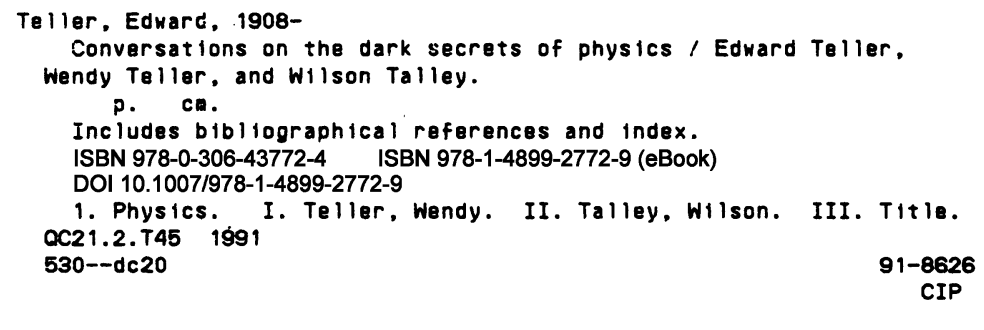

First Printing-March 1991 Second Printing - September 1991

The poem "Perils of Modern Living" reprinted by permission; (c) 1956, 1984 The New Yorker Magazine, Inc.

ISBN 978-0-306-43772-4

(C) 1991 Springer Science+Business Media New York

Originally published by Plenum Publishing Corporation, New York in 1991

Softcover reprint of the hardcover 1st edition 1991

\section{All rights reserved}

No part of this book may be reproduced, stored in a retrieval system, or transmitted in any form or by any means, electronic, mechanical, photocopying, microfilming, recording, or otherwise, without written permission from the Publisher 
This book is dedicated to the Fannie and John Hertz Foundation 


\section{PREFACE}

The idea for this book began over four decades ago when Edward Teller began teaching physics appreciation courses at the University of Chicago.

Then, as now, Dr. Teller believes that illiteracy in science is an increasingly great danger to American society, not only for our children but also for our growing adult population.

On one hand, the future of every individual on this globe is closely related to science and its applications. Fear of the results of science, which has become prevalent in much of the Western World, leads to mistaken decisions in important political affairs. But this book speaks of no fears and of no decisions-only of the facts that can prevent one of them and indirectly guide the others.

From the perspective of this book, a second point is even more 
significant. The first quarter of this century has seen the most wonderful and philosophically most important transformation in our thinking. The intellectual and aesthetic values of the points of view of Einstein and Bohr cannot be overestimated. Nor should they be hidden at the bottom of tons of mathematical rubble.

Our young people must be exposed to science both because it is useful and because it is fun. Both of these qualities should be taken at a truly high value.

Adults should be interested in science because it is a part of our cultural heritage and because the new technologies that are entering our society should be understood by as many of us as is possible.

It is our hope that this book will enable many otherwise-educated adults to catch up on the new physics so that they can properly contribute to the dialogue on the scientific and technological decisions that will shape our future. Also, we invite them to join us in an appreciation in the sheer joy of science.

The reader will find that equations are used in the text. Some writers avoid any and all equations, fearing that they will frighten off readers. We have deliberately included them to summarize the words in the text, and the lay reader need not be afraid to glance at them and even make a small attempt to decode them (the key to the code is always provided in the text). Like the sketches which also illustrate the words in this book, equations should be thought of as a form of summary.

To capture the essence of his lectures, Dr. Teller and his daughter, Wendy, began working on a manuscript. (As you will see, the footnotes in the text sometimes contain a dialogue between ET and WT.) They were joined in their effort by Wilson Talley (who also appears in the footnotes, joining the original WT).

The precipitating event that led to the completion of this book was an action by the Fannie and John Hertz Foundation. The Foundation, established by the founder of the Hertz Corporation and the Yellow Cab Company, began a series of experiments in undergraduate education, including students at primary and secondary schools. Among other projects, it was decided that Dr. Teller would be sup- 
ported in teaching an updated "Physical Sciences Appreciation" course to high school students and teachers in the Livermore Valley area of California. The course was sponsored by the Foundation, the University of California, Davis/Livermore Department of Applied Science, and the Lawrence Livermore National Laboratory. We are indebted to those literally hundreds of students, as well as the thousands who have heard Dr. Teller speak on the appreciation of science over the past decades.

Along the way to completing this book, we owe a particular debt to several individuals. Paul Teller, Edward's son, read portions of the manuscript. Joanne Smith, Patty French, and Judy Shoolery took dictation, typed, and retyped various parts. Helen Talley, Wilson's wife, entered much of the original manuscript into the Macintosh and then gamely read subsequent versions for intelligibility. Because the "proof of concept" of the book was the course given at Livermore, we should credit Sue Anderson, Matt DiMercurio, Tom Harper, Barbara Nichols, Jaci Nissen, Maria Parish, Kathryn Smith, and Charlie Westbrook for their assistance in keeping that activity on line. 


\section{CONTENTS}

Prologue-A Warning $\quad 1$

1. Relativity: Space and Time of the Physicist 3

2. Statics: The Science of No Motion 21

3. A Revolution Ignored, A Revolution Repressed 37

4. Newton 51

5. "Hypotheses Non Fingo" 69 
6. Statistical Mechanics: Disorder Is also a Law 81

7. Electricity and Magnetism or The Structure of Vacuum 95

8. The Existence of Atoms

9. The Correspondence Principle: A New Science Based on a Contradiction 129

10. Wave-Particle Dualism 145

11. The Uncertainty Principle 171

12. Uses of New Knowledge 189

Epilogue: After the Revolution 213

Answers 223

Index 239 